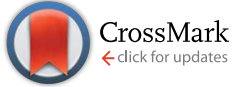

Cite this: RSC Adv., 2017, 7, 12309

Received 20th December 2016 Accepted 13th February 2017

DOI: $10.1039 / c 6 r a 28464 \mathrm{~g}$

rsc.li/rsc-advances

\section{Effects of solution treatment and aging on the microstructure, mechanical properties, and corrosion resistance of a $\beta$ type $\mathrm{Ti}-\mathrm{Ta}-\mathrm{Hf}-\mathrm{Zr}$ alloy}

\author{
Jixing Lin, ${ }^{\text {ab }}$ Sertan Ozan, ${ }^{c}$ Khurram Munir, ${ }^{d}$ Kun Wang, ${ }^{b}$ Xian Tong, ${ }^{b}$ Yuncang Li, ${ }^{d}$ \\ Guangyu Li*a and Cuie Wen*d
}

Titanium and some of its alloys have become increasingly important for biomedical materials due to their high specific strength, good corrosion resistance, and excellent biocompatibility compared to the biomedical stainless steels and cobalt-chromium based alloys. In this study, a $\beta$ type TTHZ alloy $(\mathrm{Ti}-40 \mathrm{Ta}-22 \mathrm{Hf}-11.7 \mathrm{Zr}$ ) was prepared with the cold-crucible levitation technique. The corrosion behavior and the effects of solution treatment (ST) and aging on the microstructures and mechanical properties of the TTHZ alloy were investigated using electrochemical analysis, XPS (X-ray photoelectron spectroscopy), OM (optical microscopy), XRD (X-ray diffractometry), TEM (transmission electron microscopy) and compressive testing. The results indicate that the as-cast alloy exhibited a $\beta+\omega_{\text {ath }}$ microstructure, which transformed into a single $\beta$ phase after ST at $900{ }^{\circ} \mathrm{C}$ for $1 \mathrm{~h}$. The $\beta$ phase further transformed into $\beta+\alpha^{\prime \prime}, \beta+\alpha^{\prime \prime}+\alpha$, and $\beta+\alpha+\omega_{\text {iso }}$ after aging for 15 min, $1.5 \mathrm{~h}, 12 \mathrm{~h}$ and $24 \mathrm{~h}$, respectively. The different phases of the TTHZ alloy showed significantly different mechanical properties and corrosion behavior. The solution-treated $\Pi \mathrm{THZ}$ alloy exhibited a compressive yield strength of approximately $1018 \mathrm{MPa}$ and an excellent compressive strain as no fracturing was observed; and the compression tests were stopped at a compressive strain of $\sim 70 \%$. The $T \mathrm{THZ}$ alloy after solution treatment plus aging exhibited an increase in the compressive yield strength with a decreased compressive strain. The solution-treated $\mathrm{TTHZ}$ alloy exhibited a single $\beta$ phase with the highest corrosion resistance, compared to the as-cast and solution-treated alloy, followed by aging samples. The opencircuit potential (OCP) analysis indicates that the corrosion resistance of the as-cast TTHZ alloy was superior to those of both CP-Ti and Ti6Al4V.

\section{Introduction}

Titanium and some of its alloys are receiving increasing research interest due to their high specific strength, excellent corrosion resistance, superior biocompatibility and lower elastic modulus compared to biomedical stainless steels and cobalt-chromium alloys. ${ }^{1-4}$ Apart from orthopedic and dental biomedical applications, biomedical titanium alloys are also being explored as cardiovascular stent materials..$^{5-8}$ In recent years, titanium alloy stents have been increasingly used in the treatment of stenosis in human body cavities. ${ }^{7,8}$ The stents are divided into winding, mesh, and tubular stent types. At present, laser-cutting technology has been used in the manufacture of

${ }^{a}$ College of Materials Science and Engineering, Jilin University, Changchun, Jilin 130025, China. E-mail: guangyu@jlu.edu.cn

${ }^{b}$ Advanced Material Research and Development Center, Zhejiang Industry \& Trade Vocational College, Wenzhou, Zhejiang 325003, China

${ }^{c}$ Department of Mechanical Engineering, Bozok University, Yozgat 66100, Turkey

${ }^{d}$ School of Engineering, RMIT University, Melbourne, Victoria 3001, Australia. E-mail: cuie.wen@rmit.edu.au tubular stents. Our previous study ${ }^{9}$ demonstrated that the as-cast Ti-40Ta-22Hf-11.7Zr (TTHZ) alloy exhibited high strength (compressive yield strength, tensile strength, and tensile yield strength), high elastic admissible strain $(1.58 \%$, compared to $0.21-0.31 \%$ for the Co-Cr alloy), high microhardness, and excellent cytocompatibility; such characteristics are of great significance for the alloy's ability to be used as selfexpanding stent material. The present study explores further improvement in its mechanical properties through the process of solution treatment (ST) and aging, and examines the corrosion resistance of the alloy, which is one of the most important parameters in assessing metallic biomaterials.

Similar to ferrous metals, beta $(\beta)$ type titanium alloys experience various phase transitions during solution and aging treatments, and their mechanical properties including strength, hardness, and Young's modulus are affected by the ST temperature and the aging time, so performance optimization can be achieved through tuning the ST and aging parameters. $^{\mathbf{1 0 , 1 1}}$ Previous studies ${ }^{\mathbf{1 2 - 1 5}}$ reported that ST followed by quenching involved phase transitions of the metastable $\beta$ phase, and/or athermal omega ( $\left.\omega_{\text {ath }}\right)$ phase, and/or martensite 
$\left(\alpha^{\prime \prime}\right)$ phase in $\beta$ type titanium alloys, where the $\omega_{\text {ath }}$ produced through quenching was different from the isothermal omega $\left(\omega_{\text {iso }}\right)$ phase produced during aging. In general, $\beta$ titanium alloys exhibit an unstable microstructure consisting of metastable $\beta$ and $\omega_{\text {ath }}$ phases, or a single metastable $\beta$ phase after solid solution. Titanium alloys with such microstructures are not suitable for long-term implant applications due to their unstable mechanical properties. Therefore, aging treatment is commonly conducted on titanium alloys to achieve a stable microstructure; otherwise a thermomechanical process is necessary. Yi et al. ${ }^{15}$ studied the structure transition of the Ti$7 \mathrm{Nb}-10 \mathrm{Mo}$ alloy at different aging temperatures and times and their results showed that, when conducting aging treatment at 350 to $400{ }^{\circ} \mathrm{C}, 500{ }^{\circ} \mathrm{C}$, and 600 to $650^{\circ} \mathrm{C}$, the structure transition followed: $\beta+\omega_{\text {ath }} \rightarrow \beta+\omega_{\text {iso }}, \beta+\omega_{\text {ath }} \rightarrow \beta+\omega_{\text {iso }}+\alpha$ and $\beta+\omega_{\text {ath }}$ $\rightarrow \beta+\alpha$, respectively. In another study, Xu et al. ${ }^{12}$ indicated that the transition of the martensite $\alpha^{\prime \prime}$ phase in a Ti-Nb-Ta-Zr-Fe alloy was: $\alpha^{\prime \prime} \rightarrow \alpha^{\prime \prime}+\beta \rightarrow \beta+\omega \rightarrow \beta+\alpha$ during aging. In conclusion, under conditions of different aging temperatures and durations, the phase transitions of the alloy are different; and a stable microstructure of $\alpha+\beta$ phases can be reached with use of a suitable aging temperature and time.

Furthermore, because stents in blood vessels are immersed in blood for a long period, they are easily corroded due to body temperature and the physiological environment. The corrosion products are likely to produce toxicity. For this reason, stents have to be produced from materials with high corrosion resistance. This means that the corrosion rate is sufficiently low from the view-point of the lifetime of the stents. The release of metal ions from passive and noble metals and alloys continues at a low level inside the human body. ${ }^{16} \mathrm{~A}$ number of physiological solutions simulating the body-fluid environment are currently being used for studying the corrosion of metallic biomaterials. The most commonly used physiological solutions include Ringer's solution, ${ }^{17,18}$ Hank's balanced salt solution, ${ }^{19}$ and simulated body fluid. ${ }^{20}$ In this study, we have chosen Hank's solution as the corrosion medium because it provides a sufficient proportion of salt ions and it performs to maintain a neutral $\mathrm{pH}$.

Titanium alloys, as potential materials to be used in selfexpanding stents, need adequate strength and hardness in order to expand in vessels and so support vessel walls. ${ }^{21}$ Under the same conditions, materials with higher strength can be designed with thinner stent walls to work as supports. ${ }^{22}$ This is conducive to blood circulation; however, thin struts increase the contact area between the materials and blood, accelerating corrosion of the materials, thus calling for a higher corrosion resistance. This study investigated the corrosion behavior and the effects of solution treatment and aging on the microstructure and mechanical properties of the TTHZ alloy for potential self-expanding stent applications.

\section{Materials and methods}

\section{Material}

A $\beta$ type titanium alloy, namely Ti-40Ta-22Hf- $11.7 \mathrm{Zr}$ (TTHZ), was fabricated with a cold-crucible levitation melting method using high-purity sponge titanium (Ti) and sponge hafnium (Hf), commercial pure zirconium (Zr), and high-purity tantalum (Ta) powder as raw materials. Ingots of the alloys were remelted five times in order to guarantee chemical homogeneity. Plates with a thickness of $7.5 \mathrm{~mm}$ cut from the ingots through electrical discharge machining (EDM) were subjected to solution treatment at $900^{\circ} \mathrm{C}$ (above the $\beta$ transus temperature) for $1 \mathrm{~h}$ in an argon (Ar) gas atmosphere, followed by water quenching (WQ). The plates were subjected to ST, and then aged at $300{ }^{\circ} \mathrm{C}$ for $15 \mathrm{~min}, 1.5 \mathrm{~h}$, $12 \mathrm{~h}$ and $24 \mathrm{~h}$ in Ar, followed by air cooling. All samples were loaded into quartz tubes before solution and aging treatments, followed by vacuum sealing. The solution and aging treatment process is shown schematically in Fig. 1 . The solution-treated samples are designated ST, and the solution-treated samples followed by aging for $15 \mathrm{~min}, 1.5 \mathrm{~h}, 12 \mathrm{~h}$ and $24 \mathrm{~h}$ are designated STA-15 min, STA-1.5 h, STA-12 h and STA-24 h, respectively.

\section{Microstructural characterization}

The microstructure of the TTHZ alloy after solution and aging treatments for different times was examined using optical microscopy (OM, Leica DM2500, Germany). The samples for OM observation were ground via silicon carbide (SiC) paper, polished with colloidal $\mathrm{SiO}_{2}$ to a mirror finish and then etched with Kroll solution (distilled water $100 \mathrm{~mL}$, nitric acid $5 \mathrm{~mL}$, and hydrofluoric acid $3 \mathrm{~mL}$ ). The phase constitutions of the TTHZ alloy samples were determined by X-ray diffractometry (XRD, D/max-2500PC Rigaka Japan) using $\mathrm{Cu} \mathrm{K} \alpha$ radiation over the range $20^{\circ} \leq 2 \theta \leq$ $90^{\circ}$ with an accelerating voltage of $40 \mathrm{kV}$ and a current of $250 \mathrm{mV}$ at room temperature. The samples were scanned at $2^{\circ} \mathrm{min}^{-1}$.

For transmission electron microscopy, disc samples with a diameter of $3 \mathrm{~mm}$ were mechanically punched from the TTHZ alloy samples. The discs were then manually ground to $100 \mu \mathrm{m}$ thickness using SiC papers up to 2400 grit. The samples were then ultra-sonicated in pure ethanol solvent for 180 seconds, followed by drying at room temperature. Argon-ion milling of the ground samples was performed using a JEOL ion-slicer 09100IS under high vacuum. Voltage was maintained at 6.5 $\mathrm{kV}$ with a beam current of $8 \mathrm{~mA}$ and tilt argon gun angle of 4 . Samples were ion-milled for $1.5 \mathrm{~h}$ until a hole was created at the center. The thin region around the hole was approximately $100 \mathrm{~nm}$ thick, which is appropriate for transmission electron

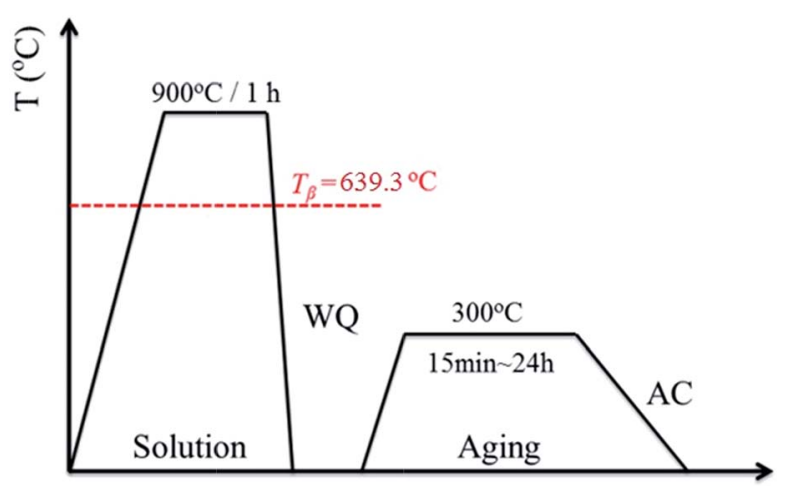

$\mathrm{t}(\mathrm{h})$

Fig. 1 Schematic heat treatment route for the TTHZ alloy. 
microscopy (TEM) imaging. Imaging and selected area electron diffraction (SAED) were performed in high-resolution TEM (JEOL 2010). Different phases in the samples were indexed using the $d$ spacing data obtained from XRD analysis.

\section{Mechanical property testing}

Cylindrical samples with dimensions of diameter $5 \mathrm{~mm}$ and 8 $\mathrm{mm}$ were machined using EDM for compression tests. The compressive properties of the TTHZ alloy samples were evaluated using an MTS testing system with a deformation rate of 0.5 $\mathrm{mm} \min ^{-1}$ at room temperature. At least five samples were tested for each group of samples and the property data are the averaged values. The compressive yield strength, ultimate compressive strength, and compressive strain of the TTHZ samples after ST at $900{ }^{\circ} \mathrm{C}$ for $1 \mathrm{~h}$, and ST plus aging at $300{ }^{\circ} \mathrm{C}$ for different times from $15 \mathrm{~min}$ to $24 \mathrm{~h}$ were obtained from the compressive stress-strain curve.

\section{Corrosion analysis}

Electrochemical experiments were carried out to evaluate the corrosion resistance of the TTHZ alloy disc specimens. A potentiostat (Princeton Applied Research PARstat 2273a) was used for the testing with a saturated calomel electrode (SCE) as the reference electrode, a platinum foil as the counter electrode, and the specimens as the working electrode. Potentiodynamic polarization measurements were undertaken on TTHZ discs, while commercially pure (CP) Ti (ASTM Grade 2) and Ti6Al4V alloy were used as the controls. Hank's balanced salt solution (HBSS) was used as the electrolyte and the tests were maintained at $37^{\circ} \mathrm{C} \pm 0.5^{\circ} \mathrm{C}$ in a water bath. The HBSS consisted of
$\mathrm{NaCl}\left(0.1370 \mathrm{~mol} \mathrm{~L}^{-1}\right), \mathrm{KCl}\left(0.0054 \mathrm{~mol} \mathrm{~L}{ }^{-1}\right), \mathrm{CaCl}_{2} \cdot 2 \mathrm{H}_{2} \mathrm{O}$ $\left(0.0013 \mathrm{~mol} \mathrm{~L}{ }^{-1}\right), \mathrm{Na}_{2} \mathrm{HPO}_{4} \cdot 2 \mathrm{H}_{2} \mathrm{O}\left(0.0003 \mathrm{~mol} \mathrm{~L}{ }^{-1}\right), \mathrm{K}_{2} \mathrm{HPO}_{4}$ $\left(0.0004 \mathrm{~mol} \mathrm{~L}^{-1}\right), \mathrm{MgSO}_{4} \cdot 7 \mathrm{H}_{2} \mathrm{O}\left(0.0010 \mathrm{~mol} \mathrm{~L}^{-1}\right)$, and $\mathrm{NaHCO}_{3}$ $\left(0.0042 \mathrm{~mol} \mathrm{~L}^{-1}\right) .{ }^{19}$ Prior to testing, the specimens were ground to 2400 grit, and cleaned in acetone, ethanol and deionized water in an ultrasonic bath, consecutively. The open circuit potential (OCP) testing of each specimen was stabilized by $2.5 \mathrm{~h}$ in HBSS. At the end of the exposure of $2.5 \mathrm{~h}$, measurements were conducted over the range of -0.8 to $2.5 \mathrm{~V}$, with a scan rate of $1 \mathrm{mV} \mathrm{s}^{-1}$. The chemical composition of the passive films were conducted using Thermo K-alpha X-ray photoelectron spectrometer (XPS). The natural corrosion current density $\left(i_{\text {corr }}\right)$ and natural corrosion potential $\left(E_{\text {corr }}\right)$ were determined by the Tafel method. The corrosion rate (CR) was determined using Faraday's law as outlined in the standard ASTM: G102, ${ }^{19}$ given by:

$$
\mathrm{CR}=K \times \frac{i_{\text {corr }}}{\rho} \times \frac{1}{\sum \frac{n_{i} f_{i}}{w_{i}}}
$$

where $K$ is a constant, $3.27 \times 10^{-3}, \mathrm{~mm} g$ per $(\mu \mathrm{A} \mathrm{cm}$ year $) ; i_{\text {corr }}$ is the corrosion current density in $\mu \mathrm{A} \mathrm{cm}^{-2} ; \rho$ is the density of the sample in $\mathrm{g} \mathrm{cm}^{-3} ; n_{i}$ is the valence of the $i^{\text {th }}$ element of the alloy; $f_{i}$ is the mass fraction of the $i^{\text {th }}$ element of the alloy; and $W_{i}$ is the atomic weight of the $i^{\text {th }}$ element of the alloy.

\section{Results and discussion}

\section{Material characterization}

Fig. 2 shows the microstructures of the TTHZ alloy after different heat treatments: the alloy, in different states, consists of a $\beta$ phase, showing clear grain boundaries. The grain size of
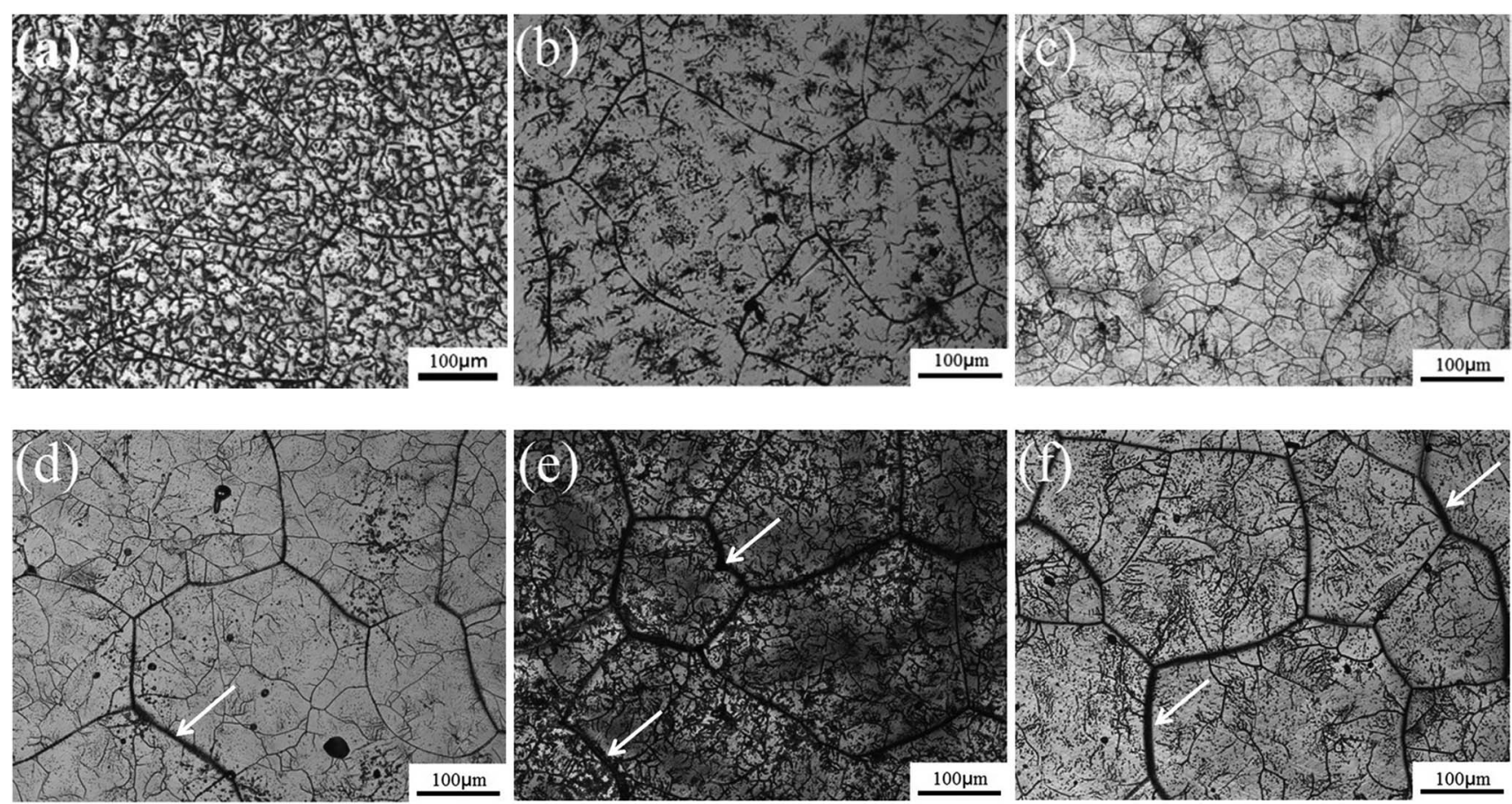

Fig. 2 Optical micrographs of TTHZ alloy: (a) as-cast, (b) solution-treated, (c) solution-treated plus aging for 15 min, (d) solution-treated plus aging for $1.5 \mathrm{~h}$, (e) solution-treated plus aging for $12 \mathrm{~h}$, and (f) solution-treated plus aging for $24 \mathrm{~h}$. 


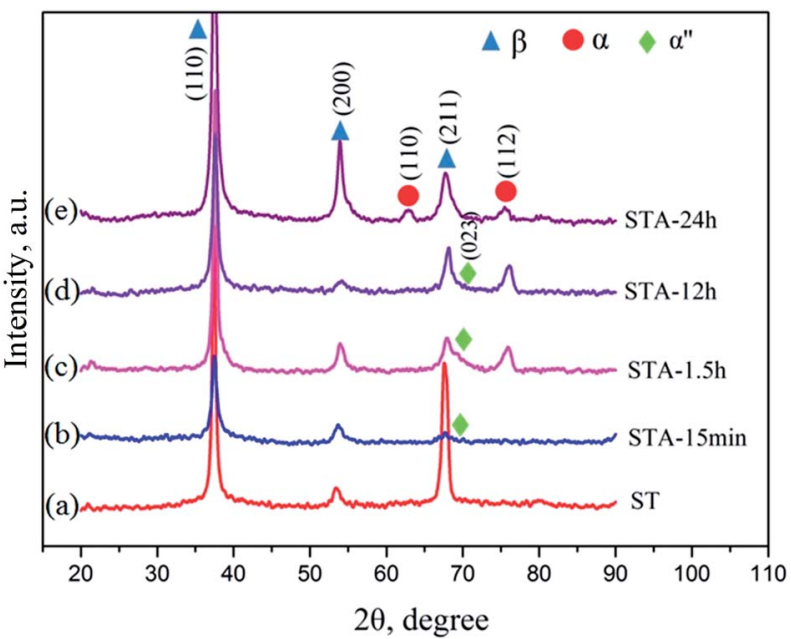

Fig. 3 XRD patterns of TTHZ alloy samples under different heat treatment processes: (a) solution-treated, (b) solution-treated plus aging for $15 \mathrm{~min}$, (c) solution-treated plus aging for $1.5 \mathrm{~h}$, (d) solutiontreated plus aging for $12 \mathrm{~h}$, and (e) solution-treated plus aging for $24 \mathrm{~h}$.

the as-cast TTHZ sample (Fig. 2a) is smaller than that of the solution-treated samples (Fig. 2b) and the solution-treated plus aging samples (Fig. 2c-f). This is because the ST temperature exceeded the $\beta$ phase transformation point and the grains of the $\beta$ phase were readily coarsened during the ST holding process. As can be seen in Fig. 2b, large grains are clearer than those seen in the as-cast state due to the ST. Samples after ST followed by aging from $15 \mathrm{~min}$ to $24 \mathrm{~h}$ show a second set of finer grains with clear grain boundaries inside the large grains; while, as the aging time increased from $1.5 \mathrm{~h}$ and $24 \mathrm{~h}$, the large grain boundaries became thicker, as indicated by the white arrows in Fig. 2d-f.

Fig. 3 shows the X-ray diffraction patterns of the TTHZ alloy samples after different heat treatments. The as-cast ${ }^{9}$ and solution-treated alloy samples comprised a single $\beta$ phase. When the aging time was $15 \mathrm{~min}$, an $\alpha^{\prime \prime}$ phase appeared. As the aging time increased to $1.5 \mathrm{~h}$, an $\alpha$ phase emerged. When the aging time reached $24 \mathrm{~h}$, the $\alpha^{\prime \prime}$ phase disappeared and two peaks attributable to an $\alpha$ phase appeared, indicating transition of the $\alpha^{\prime \prime}$ phase to the $\alpha$ phase in STA-24 h samples.

To further confirm whether a small amount of the $\omega$ phase, or a small amount of other phases, were contained in the alloy but were not detected by XRD characterization, TEM analysis was conducted on the alloy in its solution-treated state and after being subjected to $24 \mathrm{~h}$ of aging treatment. Fig. 4 shows a typical bright-field TEM image and the corresponding SAED pattern of the ST specimen. The results indicate that the alloy was composed of a single $\beta$ phase in a solid solution state, suggesting that no $\omega_{\text {ath }}$ or $\alpha^{\prime \prime}$ phases appeared during WQ, which is consistent with the XRD results. Fig. 5 shows the bright field TEM image and corresponding SAED pattern of the STA alloy after aging for $24 \mathrm{~h}$. In addition to those $\beta$ and $\alpha$ phases of the alloy evidenced by XRD, an isothermal $\omega_{\text {iso }}$ phase was observed. Our previous study demonstrated that a small amount of $\omega_{\text {ath }}$ phase was detected through TEM in the as-cast TTHZ alloy, but was not found in the XRD pattern due to its small concentration and small size of phases. A similar phenomenon was observed in $\mathrm{Ti}-30 \mathrm{Zr}-7 \mathrm{Mo}{ }^{23} \mathrm{TiNb}_{24} \mathrm{Zr}_{2}$ (ref. 24) and Ti-19Zr-10Nb-1Fe. ${ }^{25}$

The average bond orders $\left(\overline{B_{0}}\right)$, average metal d-orbital energy levels $\left(\overline{\mathbf{M}_{\mathrm{d}}}\right), \mathrm{Mo}_{\text {eq. }}$ and $e / a$ ratio of the TTHZ alloy in this study were $2.942,2.590,8.8$, and 4.216, respectively. ${ }^{9}$ After ST followed by WQ in the $\beta$ phase region, the alloy showed a metastable $\beta$ phase (Fig. 3a and 4). Based on molecular orbital theory, Morinaga et $a .^{26}$ indicated the relationships between the $\beta$ transition temperature $T_{\beta}\left({ }^{\circ} \mathrm{C}\right)$ with $\overline{\mathrm{B}_{\mathrm{o}}}$ and $\overline{\mathrm{M}_{\mathrm{d}}}$ values of a titanium alloy, given by:

$$
T_{\beta}=10^{2}\left(40.65-1.052 \overline{\mathrm{M}_{\mathrm{d}}}-9.79 \overline{\mathrm{B}_{\mathrm{o}}}-273\right)
$$

By substituting $\overline{\mathrm{B}_{\mathrm{o}}}$ and $\overline{\mathrm{M}_{\mathrm{d}}}$ values of the TTHZ alloy into eqn (2), the $T_{\beta}$ for the TTHZ alloy can be calculated as $639.3^{\circ} \mathrm{C}$. On the other hand, from the perspective of the influences of the alloying elements on the $\beta$ transition temperature, $\mathrm{Hf}$ and $\mathrm{Zr}$ are basically neutral elements, because they lower the $\alpha / \beta$ transition temperature only slightly. ${ }^{27}$ Also, $\mathrm{Hf}$ and $\mathrm{Zr}$ are isomorphous
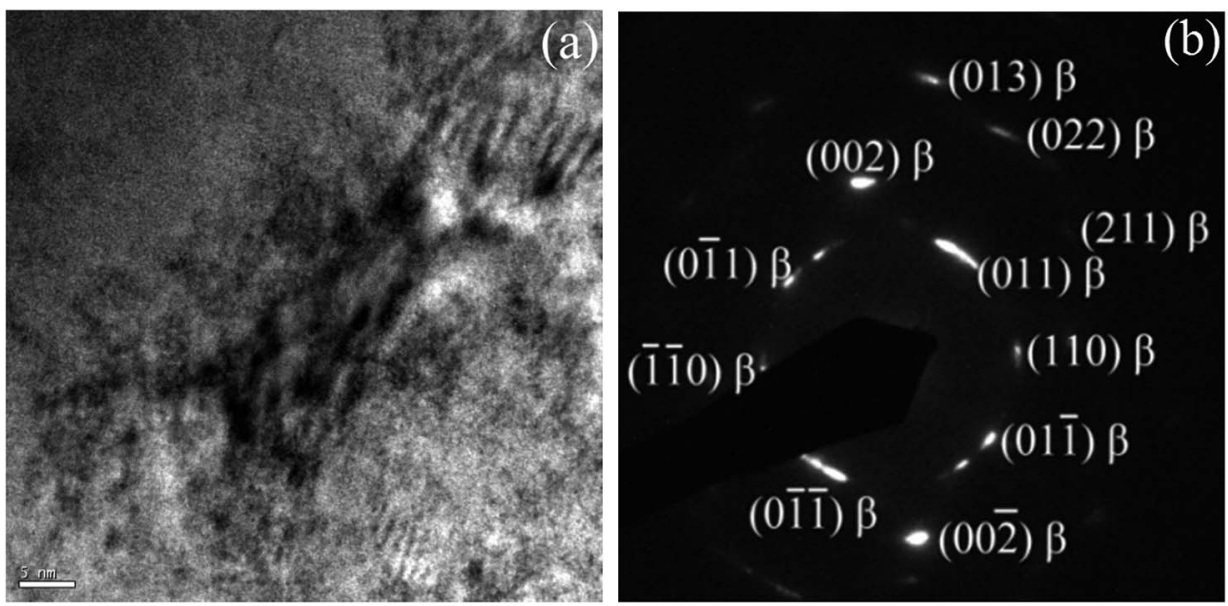

Fig. 4 (a) Bright field TEM image of solution-treated TTHZ specimen, and (b) the corresponding electron diffraction pattern. 

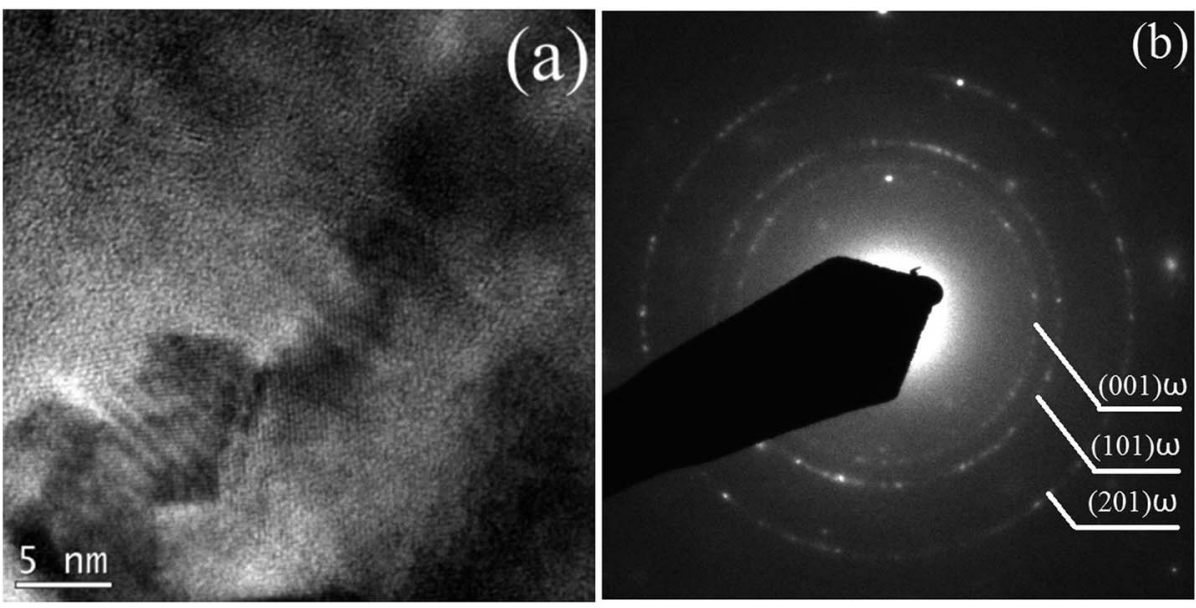

Fig. 5 (a) Bright field TEM image, and (b) the corresponding SAED pattern of TTHZ alloy under the STA-24 h pattern.

with titanium, exhibit the same $\beta$ to $\alpha$ allotropic phase transformation and have complete solubilities in $\alpha$ and $\beta$ phases of titanium; while Ta is an isomorphous $\beta$ stabilizer and lowers the $\alpha / \beta$ transition temperature. ${ }^{27}$ Hence, the $\beta$ transition temperature of the TTHZ alloy can be deduced to be lower than that of pure titanium $\left(882.5{ }^{\circ} \mathrm{C}\right)$. Therefore, the ST temperature of $900{ }^{\circ} \mathrm{C}$ for the TTHZ alloy in this study ensured the transformation to a single metastable $\beta$ phase, as evidenced by the XRD and TEM results.

The metastable $\beta$ phase obtained from ST was transformed into new phases during the subsequent aging treatment. The XRD results reveal that a martensite $\alpha^{\prime \prime}$ phase appeared in the alloy after aging for $15 \mathrm{~min}$ and this phase still existed after aging for $12 \mathrm{~h}$. According to its formation process, martensite $\alpha^{\prime \prime}$ can be divided into isothermal, quenching, and stress induced martensite. A stress-induced martensite $\alpha^{\prime \prime}$ was observed in the $\beta$ type titanium alloys of Ti-10V-2Fe-3Al (Ti1023) under compressive loading ${ }^{28}$ and of Ti-33.6Nb-4Sn after groove-rolling, swaging and cyclic tensile deformation..$^{29}$ In this study, martensite $\alpha^{\prime \prime}$ appeared in the TTHZ alloy after aging instead of WQ and the resultant martensite was isothermal. Dobromyslov et al. ${ }^{30}$ indicated that the proportion of $\beta$ stabilizers in titanium alloys significantly affected the formation of martensite. Davis et al. ${ }^{31}$ studied the effects of molybdenum (Mo) content on martensitic transition in Ti-Mo alloys and indicated that the alloys Ti-2-4(wt\%)Mo transformed into hexagonal martensite $\left(\alpha^{\prime}\right)$ on WQ from $\beta$ field, while the alloys Ti-4-8(wt\%)Mo transformed into orthorhombic martensite $\left(\alpha^{\prime \prime}\right)$; moreover, when the Mo content reached $10 \mathrm{wt} \%$, the alloy transformed into a single $\beta$ phase. In this study, the molybdenum equivalence ( $\left.\mathrm{Mo}_{\text {eq. }}\right)^{32}$ of the TTHZ alloy is $8.8,{ }^{9}$ and the martensite phases $\alpha$ and $\alpha^{\prime \prime}$ did not appear after WQ but did so after aging, followed by the reconstruction of lattices which drove the transition of the original body-centered cubic (bbc) $\beta$ phase to the orthorhombic martensite $\alpha^{\prime \prime}$ phase. The martensite $\alpha^{\prime \prime}$ phase exhibited unstable thermodynamic properties and phase transformations took place during the aging process. The XRD results show that, after aging for $1.5 \mathrm{~h}$, the $\alpha^{\prime \prime}$ phase started to transform into an $\alpha$ phase and the phase transformation completed after aging for $24 \mathrm{~h}$. It can be concluded that the phases of the TTHZ alloy from as-cast state, solid solution, solid solution plus aging for $24 \mathrm{~h}$ followed the transitions: $\beta+\omega_{\text {ath }} \rightarrow \beta \rightarrow \beta+\alpha^{\prime \prime} \rightarrow \beta+\alpha^{\prime \prime}+\alpha \rightarrow \beta+\alpha+\omega_{\text {iso }}$.

\section{Mechanical properties}

Fig. 6 shows the compressive strain-stress curves of the TTHZ alloy in different states, and Table 1 shows the corresponding compressive yield strengths and compressive strains. It can be seen that the compressive yield strength decreased from $1154.0 \pm$ 31.2 MPa for the as-cast alloy to 1018.1 $\pm 1.4 \mathrm{MPa}$ for the alloy after ST, and then increased to $1481.8 \pm 27.5 \mathrm{MPa}$ for the alloy after ST followed by aging for $15 \mathrm{~min}$ (STA-15 min). Thereafter, the yield strength of the solution-treated alloy declined to 1424.4 $\pm 12.8 \mathrm{MPa}$ after aging for $1.5 \mathrm{~h}$ (STA-1.5 $\mathrm{h}$ ), to $1112.5 \pm 10.1 \mathrm{MPa}$ after aging for $12 \mathrm{~h}$ (STA-12 h), and to $1154.8 \pm 24.5 \mathrm{MPa}$ after aging for $24 \mathrm{~h}$ (STA-24 h). Moreover, in the as-cast and solid

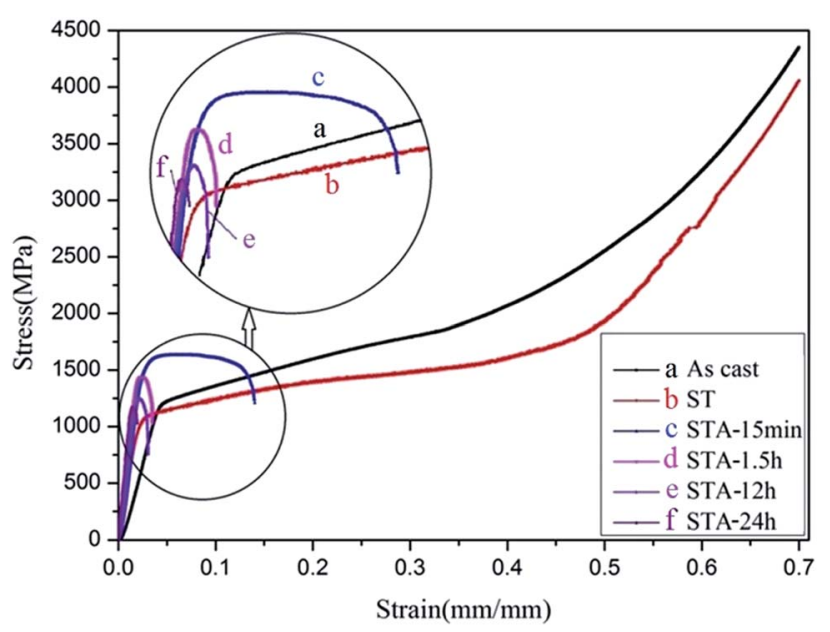

Fig. 6 Compressive stress-strain curves of TTHZ alloy samples after different heat treatment processes: (a) as-cast, (b) solution-treated, (c) solution-treated plus aging for $15 \mathrm{~min}$, (d) solution-treated plus aging for $1.5 \mathrm{~h}$, (e) solution-treated plus aging for $12 \mathrm{~h}$, and (f) solutiontreated plus aging for $24 \mathrm{~h}$. 
Table 1 Compressive properties of TTHZ alloy after different heat treatment processes

\begin{tabular}{lll}
\hline Process conditions & $\begin{array}{l}\text { Compressive yield } \\
\text { strength (MPa) }\end{array}$ & $\begin{array}{l}\text { Compressive } \\
\text { strain }(\%)\end{array}$ \\
\hline As-cast & $1154.0 \pm 31.2$ & $>70.0$ \\
ST & $1018.1 \pm 1.4$ & $>70.0$ \\
STA-15 min & $1481.8 \pm 27.5$ & $14.3 \pm 3.1$ \\
STA-1.5 h & $1424.4 \pm 12.8$ & $2.9 \pm 0.7$ \\
STA-12 h & $1159.7 \pm 80.2$ & $2.7 \pm 0.5$ \\
STA-24 h & $1154.8 \pm 24.5$ & $2.3 \pm 0.9$
\end{tabular}

solution states, the alloy showed excellent plastic deformation ability, as no fracturing was observed; and the compression tests were stopped at a compressive strain of $\sim 70 \%$. With the aging process, however, the plasticity of the alloy decreased rapidly. To sum up, the compressive yield strengths of the TTHZ alloys after different heat treatment processes range from 1018.1 to 1481.8 MPa, compared to $256 \mathrm{MPa}$ for $\mathrm{cp}-\mathrm{Ti}^{3}{ }^{33}$ The compressive yield strength of the TTHZ alloy samples are 4.0-5.8 times higher than that of cp-Ti.

The phase transition of the TTHZ alloy after different heat treatments resulted in the changes in mechanical properties observed. In the as-cast state, the alloy comprised $\beta+\omega_{\text {ath }}$ phases and the $\omega_{\text {ath }}$ phase was highly dispersed with a size of about $2 \mathrm{~nm},{ }^{9}$ so the alloy showed good compression performance. After ST at $900{ }^{\circ} \mathrm{C}$ for $1 \mathrm{~h}$, the alloy became a single $\beta$ phase and its compressive yield strength was lower than that of the as-cast alloy due to the absence of an $\omega$ phase. During the aging process, the martensite $\alpha^{\prime \prime}$ phase appeared after $15 \mathrm{~min}$ aging, leading to increased yield strength of the alloy; and the greater the volume fraction of the $\alpha^{\prime \prime}$ phase, the higher the yield strength, while it adversely affected the plasticity. Wang et al. reported similar results in a Ti-Nb-Ta-Zr alloy. ${ }^{34}$ After $1.5 \mathrm{~h}$ of aging, an $\alpha$ phase was produced which is called the secondary $\alpha$ phase. This phase has been reported as strengthening the $\beta$ phase to some extent. ${ }^{35}$ Furthermore, after $24 \mathrm{~h}$ of aging, $\omega_{\text {iso }}$ was detected in the TEM analysis and the amount of the $\omega_{\text {iso }}$ phase obtained in the aging process significantly increased the yield strength of the alloy but substantially decreased the plasticity. Weiss et al. also indicated that the optimization of mechanical properties is possible through microstructure control during the different stages of the thermomechanical process such as hot rolling and forging. ${ }^{36}$ Although the different phases of $\alpha^{\prime \prime}, \alpha$, and $\omega_{\text {iso }}$ produced in the aging process resulted in increases in yield strength, they had deleterious effects on the plasticity. In addition, as the $\alpha^{\prime \prime}, \alpha$, and $\omega_{\text {iso }}$ phases appeared during aging, the compressive yield strength improved to some extent compared with that in the as-cast and the solutiontreated, while it was more likely to cause a fracture in the alloy during compression due to the increased brittleness of the alloy. Further, the compressive yield strength declined with an increase in the aging time. The existence of the $\omega_{\text {iso }}$ phase can hinder the dislocation slips and shear deformation of the matrix. Williams et al. reported that cracks were first generated on the interface between the matrix and the $\omega$ phase and expanded rapidly, resulting in the degradation of the mechanical properties of the alloy. ${ }^{37}$

\section{Electrochemical corrosion behavior}

Fig. 7 shows the OCP curves of the as-cast TTHZ alloy, CP-Ti, and Ti-6Al-4V. It can be seen that the CP-Ti was the most stable, with its OCP being about -0.05 to $-0.49 \mathrm{~V}$, while the Ti$6 \mathrm{Al}-4 \mathrm{~V}$ tended to be stable after $1 \mathrm{~h}$ and its OCP was about -0.14 to $-0.15 \mathrm{~V}$. The as-cast TTHZ alloy became stable after $2.5 \mathrm{~h}$ and its OCP was about $0.0 \mathrm{~V}$. Based on electrochemical principles, the more positive the OCP, the smaller the tendency to corrode. Therefore, it can be concluded that the corrosion resistance of the three alloys is in descending order as follows: as-cast TTHZ alloy $>\mathrm{CP}-\mathrm{Ti}>\mathrm{Ti}-6 \mathrm{Al}-4 \mathrm{~V}$.

The corrosion mechanism of titanium alloys is mainly attributed to the fact that compact and stable oxide passive films can be formed on the material surface. As for the CP-Ti, stable $\mathrm{TiO}_{2}$ was formed, while the passive films of the Ti-6Al$4 \mathrm{~V}$ were found to contain $\mathrm{Ti}_{2} \mathrm{O}_{3}$, $\mathrm{TiO}$, and $\mathrm{TiO}_{2} \cdot{ }^{38,39} \mathrm{In}$ addition, $\mathrm{Al}_{2} \mathrm{O}_{3}$ and $\mathrm{V}_{2} \mathrm{O}_{3}$ were found in the oxidation films due to the existence of aluminum (Al) and vanadium (V) in the alloy. ${ }^{40}$

Fig. 8 shows the XPS spectra for the passive film formed on the surface of the as-cast TTHZ alloy after polarization in HBSS. Apart from the peak of $\mathrm{C}$, the peaks of $\mathrm{Ti}, \mathrm{Ta}, \mathrm{Hf}, \mathrm{Zr}$ and $\mathrm{O}$ are observed in the wide scanning spectrum, as shown in Fig. 8a. The chemical composition is $12.64 \% \mathrm{Ti}, 6.32 \% \mathrm{Ta}, 3.15 \% \mathrm{Hf}$, $13.98 \% \mathrm{Zr}$ and $63.91 \% \mathrm{O}$ (at\%). It suggests that the passive film of the as-cast TTHZ alloy is also predominantly composed of $\mathrm{Ti}$ and $\mathrm{Zr}$ oxides. Fig. $8 \mathrm{~b}-\mathrm{e}$ shows the spectrum of Ti 2p, Ta $4 \mathrm{f}, \mathrm{Hf} 4 \mathrm{f}$ and $\mathrm{Zr} 3 \mathrm{~d}$ respectively, those indicating that in addition to $\mathrm{TiO}_{2}$, there are $\mathrm{Ta}_{2} \mathrm{O}_{5}, \mathrm{HfO}_{2}, \mathrm{ZrO}_{2}$, and $\mathrm{Zr}_{2} \mathrm{O}_{3}$ oxides formed in the passive film of as-cast TTHZ alloy surface.

The corrosion resistance of the TTHZ alloy can be assumed to be influenced by the alloying elements $\mathrm{Ta}, \mathrm{Hf}$, and $\mathrm{Zr}$ in this study. Zhou et al. ${ }^{41}$ studied the corrosion resistance of Ti-Ta alloys and found that with an increase in Ta content, the corrosion resistance of the alloys increased. The enthalpy of formation $\left(\Delta H_{298}\right)$ of $\mathrm{Ta}_{2} \mathrm{O}_{5}$ was $-2046 \mathrm{~kJ} \mathrm{~mol}^{-1}$, which is lower than that of $\mathrm{Al}_{2} \mathrm{O}_{3}\left(-1675 \mathrm{~kJ} \mathrm{~mol}^{-1}\right)$ and $\mathrm{V}_{2} \mathrm{O}_{3}(-1226 \mathrm{~kJ}$ $\left.\mathrm{mol}^{-1}\right) .^{42}$ Therefore, the $\mathrm{Ta}_{2} \mathrm{O}_{5}$ oxides film is more stable, making the passive films more difficult to dissolve. Niinomi

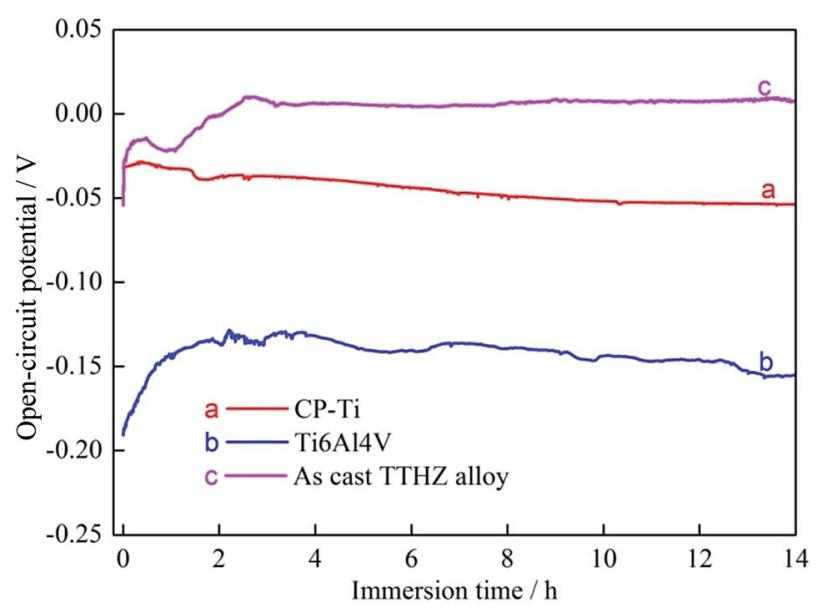

Fig. 7 Plots of open-circuit potential as a function of time: (a) CP-Ti, (b) Ti6Al4V, (c) as-cast TTHZ alloy. 

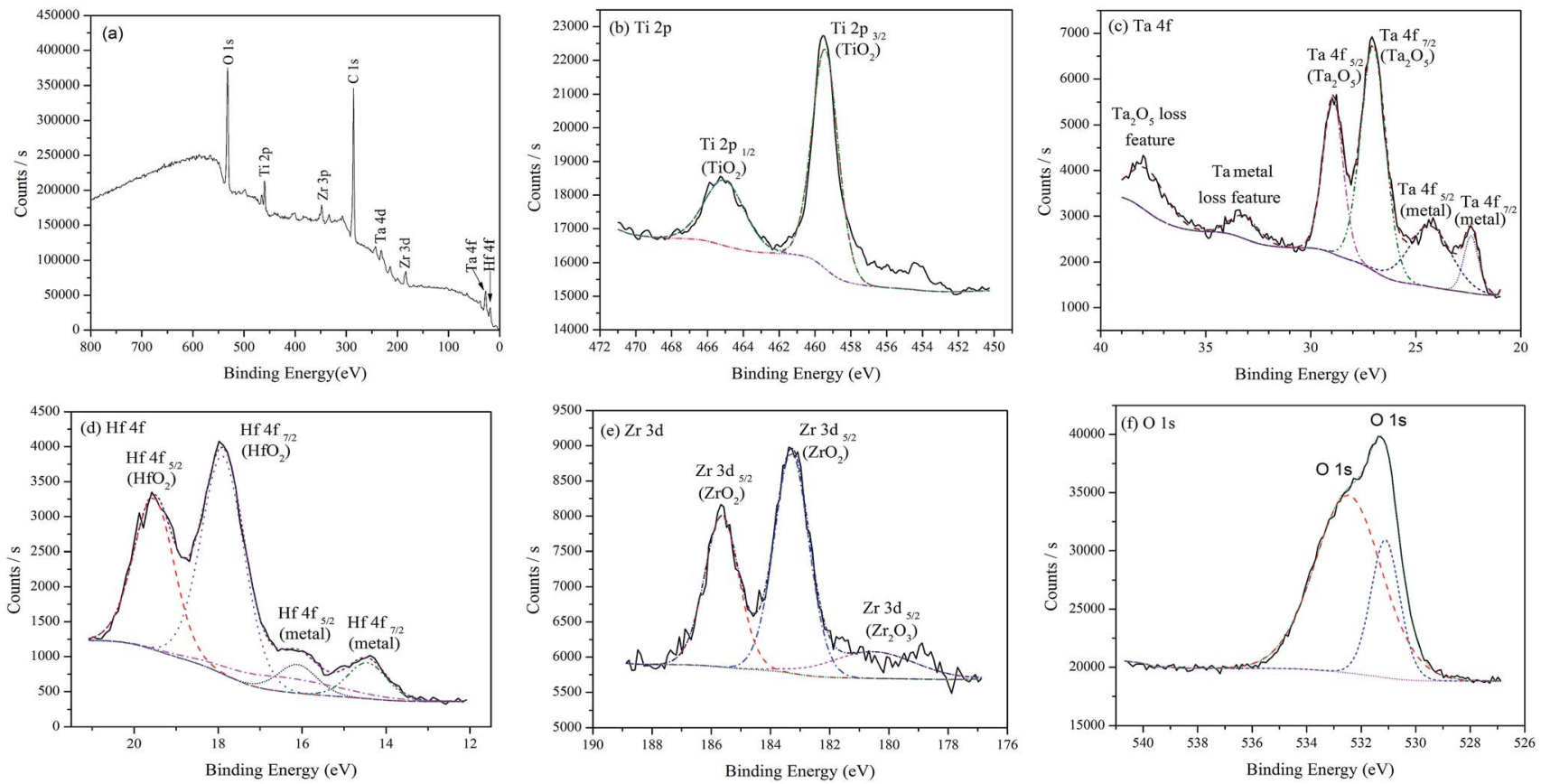

Fig. 8 XPS spectra for the surface of as-cast TTHZ alloy after polarization test: (a) wide scanning spectrum, (b) Ti 2p, (c) Ta 4f, (d) Hf 4f, (e) Zr 3d and (f) $O$ 1s spectra.

et $a .^{43}$ demonstrated that the corrosion resistance of Ti-Hf alloys was better than that of pure titanium, and passive films consisting of $\mathrm{HfO}_{2}$ and $\mathrm{TiO}_{2}$ were formed on the Ti-Hf alloy surface. Martins et al. ${ }^{44}$ investigated the influence of different $\mathrm{Zr}$ proportions on the structure and corrosion resistance of as-cast Ti-30Nb alloy and indicated that, after adding $7.5 \mathrm{wt} \%$ and 15 $\mathrm{wt} \%$ of $\mathrm{Zr}$ to the $\mathrm{Ti}-30 \mathrm{Nb}$ alloy, the corrosion resistance increased with increasing $\mathrm{Zr}$ content.

The as-cast TTHZ alloy can be classified as a $\beta$ type titanium alloy, the CP-Ti is an $\alpha$ type titanium alloy, while the Ti-6Al-4V is an $\alpha+\beta$ type titanium alloy at room temperature. The multiple phases of Ti-6Al-4V exhibited differences in thermodynamic stability, forming corrosion microcells during the electrochemical testing. Codaro et al. ${ }^{45}$ demonstrated that point corrosion frequently occurred in the interface between $\alpha$ and $\beta$ phases in the Ti-6Al-4V alloy. On the other hand, the TTHZ alloy showed better corrosion resistance than those of CP-Ti and Ti-6Al-4V, mainly because, after adding alloy elements including $\mathrm{Ta}, \mathrm{Hf}$, and $\mathrm{Zr}$, more stable and protective passive films were formed on the surface.

Fig. 9 shows the potentiodynamic polarization curves of the TTHZ alloy after different heat treatment processes in HBSS. It can be seen that the alloy in different states exhibits similar curves. Beyond the Tafel region, the corrosion current density $\left(i_{\text {corr }}\right)$ of the alloy remains unchanged with increasing potential, and the alloy was in a passive state, indicating that passive films with excellent corrosion resistance were formed on the sample surface. According to the linear nature of the gradient of the plots at this stage, the passive current was stable with a large passive potential interval (approximately $0.7 \mathrm{~V}$ to $2.5 \mathrm{~V}$ ), which illustrates that stable passive films were formed on the surface of the TTHZ alloy, thus conferring enhanced corrosion resistance.
Table 2 lists the natural corrosion potential $\left(E_{\text {corr }}\right)$, natural corrosion current density $\left(i_{\text {corr }}\right)$, and CR calculated according to Fig. 8. The results reveal that the difference in $E_{\text {corr }}$ of the alloys in all states is small, ranging from -0.075 to $0.330 \mathrm{~V} ; i_{\text {corr }}$ and CR are, in increasing order: ST $<$ STA-15 $\min <$ STA- $1.5 \mathrm{~h}<$ ascast $<$ STA-12 $\mathrm{h}<$ STA-24 h. Based on electrochemical principles, $i_{\text {corr }}$ is generally used to judge the corrosion resistance of material and the smaller the $i_{\text {corr }}$ value, the better the corrosion resistance. Further, the CR of the samples, calculated based on the corrosion current density $\left(i_{\text {corr }}\right)$, showed a positive proportional relationship. Therefore, it can be concluded that the alloy showed the highest corrosion resistance in its ST state.

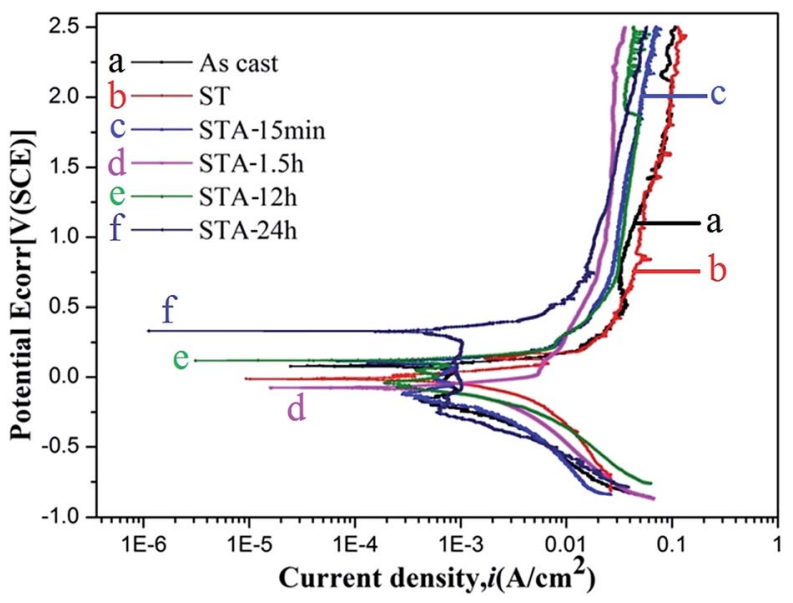

Fig. 9 Potentiodynamic polarization curves of TTHZ alloy in HBSS after different heat treatment processes: (a) as-cast, (b) solutiontreated, (c) solution-treated plus aging for $15 \mathrm{~min}$, (d) solution-treated plus aging for $1.5 \mathrm{~h}$, (e) solution-treated plus aging for $12 \mathrm{~h}$, and (f) solution-treated plus aging for $24 \mathrm{~h}$. 
Table 2 Electrochemical properties of TTHZ alloy after different heat treatment processes, determined via potentiodynamic polarization in HBSS

\begin{tabular}{lrlr}
\hline $\begin{array}{l}\text { Process } \\
\text { conditions }\end{array}$ & \multicolumn{1}{c}{$E_{\text {corr }}(\mathrm{V})$} & $i_{\text {corr }}\left(\mu \mathrm{A} \mathrm{cm}^{-2}\right)$ & \multicolumn{1}{l}{$\begin{array}{l}\mathrm{CR} \\
(\mu \mathrm{m} \text { per year })\end{array}$} \\
\hline As-cast & $0.079 \pm 0.004$ & $1.47 \pm 0.05$ & $12.9 \pm 0.4$ \\
ST & $-0.013 \pm 0.008$ & $0.49 \pm 0.03$ & $4.3 \pm 0.2$ \\
STA-15 min & $0.112 \pm 0.012$ & $0.52 \pm 0.04$ & $4.6 \pm 0.3$ \\
STA-1.5 h & $-0.075 \pm 0.005$ & $0.96 \pm 0.04$ & $8.5 \pm 0.3$ \\
STA-12 h & $0.119 \pm 0.022$ & $1.79 \pm 0.08$ & $15.8 \pm 0.6$ \\
STA-24 h & $0.330 \pm 0.034$ & $1.80 \pm 0.10$ & $15.9 \pm 0.8$
\end{tabular}

The TTHZ alloy has identical chemical compositions even after different heat treatment processes. From the perspective of passivation, the passive films formed on the alloy were the same after different treatments, so the difference in corrosion resistance of the alloy after different processes can be investigated based on the type and size of phases in the alloy. In the solution state, the alloy consisted of a single $\beta$ phase, so it showed the highest corrosion resistance. When the aging treatment was carried out for $15 \mathrm{~min}$, only a small amount of the $\alpha^{\prime \prime}$ phase appeared and the $\beta$ phase transformed into an $\alpha^{\prime \prime}$ phase without diffusion, so the corrosion resistance of the alloy tended to be the same as that in the solid solution state. For the TTHZ alloy after ST followed by aging for $1.5 \mathrm{~h}$, besides $\alpha^{\prime \prime}$, an $\alpha$ phase emerged and the corrosion resistance decreased. As the aging time increased, the $\alpha$ phase grew, leading to a further decrease in corrosion resistance; however, the corrosion resistance was better than that of the as-cast alloy, which indicates that the corrosion resistance of the alloy containing both $\alpha^{\prime \prime}$ and $\alpha$ phases was better than that of the alloy containing $\beta$ and $\omega$ phases.

\section{Conclusions}

The effects of solution treatment and aging of $\beta$ type TTHZ (Ti40Ta-22Hf-11.7Zr) alloy on the mechanical properties and corrosion resistance have been investigated in this study. The microstructure, mechanical properties, and corrosion resistance of the TTHZ alloy after different heat treatments have been evaluated and the main conclusions are summarized as follows:

(1) The results of OM, TEM, and XRD investigation show that, in the as-cast state and when subjected to solution treatment (ST) at $900{ }^{\circ} \mathrm{C}$ for $1 \mathrm{~h}$, the alloy consisted of $\beta+\omega_{\text {ath }}$ and a single $\beta$ phase, respectively. After the alloy being solutiontreated followed by aging, $\alpha^{\prime \prime}$ and $\alpha$ phases were gradually precipitated by aging treatment at $300{ }^{\circ} \mathrm{C}$ for different times ( 15 min-24 h), and an $\omega_{\text {iso }}$ phase emerged due to the transformation of $\alpha^{\prime \prime}$ with increasing aging time.

(2) In as-cast and ST states, the alloy showed excellent compression performance, with a compressive yield strength of approximately $1018 \mathrm{MPa}$ and an excellent compressive strain as no fracturing was observed; and the compression tests were stopped at a compressive strain of $\sim 70 \%$. After aging treatment, the compressive yield strength was higher than that of the ascast and solid solution-treated and then decreased with an increase in aging time.
(3) The corrosion behavior changed with changes in the phases of the TTHZ alloy samples after different heat treatments. In the solution-treated sample, the alloy with a single $\beta$ phase showed the highest corrosion resistance. The corrosion potential $\left(E_{\text {corr }}\right)$, corrosion current density $\left(i_{\text {corr }}\right)$, and corrosion rate $(\mathrm{CR})$ of the solution-treated TTHZ sample were $-0.013 \pm$ $0.008 \mathrm{~V}, 0.49 \pm 0.03 \mu \mathrm{A} \mathrm{cm} \mathrm{cm}^{-2}$, and $4.3 \pm 0.2 \mu \mathrm{m}$ per year, respectively. The OCP data show that, in its as-cast state, the corrosion resistance of the TTHZ alloy was superior to those of CP-Ti and Ti6Al4V.

\section{Acknowledgements}

This research is financially supported by the National Health and Medical Research Council (NHMRC), Australia, through grant GNT1087290. The authors acknowledge the facility, and the scientific and technical assistance of RMIT University's Microscopy and Microanalysis facility, a lined laboratory of the Australian Microscopy \& Microanalysis Research Facility.

\section{Notes and references}

1 M. Niinomi, Sci. Technol. Adv. Mater., 2003, 4, 445-454.

2 M. Niinomi, J. Artif. Organs, 2008, 11, 105-110.

3 M. Long and H. J. Rack, Biomaterials, 1998, 19, 1621-1639.

4 H. J. Rack and J. I. Qazi, Mater. Sci. Eng., C, 2006, 26, 12691277.

5 V. Biehl, T. Wack, S. Winter, U. Seyfert and J. Breme, Biomol. Eng., 2002, 19, 97-101.

6 K. Cho, M. Niinomi, M. Nakai, J. Hieda and Y. Kawasaki, Mater. Trans., 2013, 54, 574-581.

7 B. O'Brien, J. Stinson and W. Carroll, Acta Biomater., 2008, 4, 1553-1559.

8 Y. X. Tian, Z. T. Yu, C. Y. A. Ong, D. Kent and G. Wang, J. Mech. Behav. Biomed. Mater., 2015, 45, 132-141.

9 J. X. Lin, S. Ozan, Y. C. Li, D. H. Ping, X. Tong, G. Y. Li and C. E. Wen, Sci. Rep., 2016, 6, 37901.

10 M. Geetha, A. K. Singh, R. Asokamani and A. K. Gogia, Prog. Mater. Sci., 2009, 54, 397-425.

11 W. Wan, H. Liu, Y. Jiang, D. Yi, R. Yi, Q. Gao, D. Wang and Q. Yang, Mater. Sci. Eng., A, 2015, 637, 130-138.

12 Y. F. Xu, D. Q. Yi, H. Q. Liu, B. Wang and F. L. Yang, Mater. Sci. Eng., A, 2011, 529, 326-334.

13 C. R. M. Afonso, G. T. Aleixo, A. J. Ramirez and R. Caram, Mater. Sci. Eng., C, 2007, 27, 908-913.

14 K. K. Kharia and H. J. Rack, Metall. Mater. Trans. A, 2001, 32, 671-679.

15 R. W. Yi, H. Q. Liu and D. Q Yi, Mater. Sci. Eng., C, 2016, 63, 577-586.

16 S. Hiromoto, Corrosion of Metallic Biomaterials, 2010, 99-121. 17 H. Krawiec, V. Vignal, J. Loch and P. Erazmus-Vignal, Corros. Sci., 2015, 96, 160-170.

18 Y. F. Xu, Y. F. Xiao, D. Q. Yi, H. Q. Liu, L. Wu and J. Wen, Trans. Nonferrous Met. Soc. China, 2015, 25, 2556-2563.

19 A. Biesiekierski, D. H. Ping, Y. Yamabe-Mitarai and C. E. Wen, Mater. Des., 2014, 59, 303-309. 
20 H. H. Huang, C. P. Wu, Y. S. Sun, H. M. Huang and T. H. Lee, Thin Solid Films, 2013, 549, 87-92.

21 K. Cho, M. Niinomi and M. Nakai, Mater. Trans., 2013, 54, 574-581.

22 B. O'Brien and W. Carroll, Acta Biomater., 2009, 5, 945-958.

23 X. L. Zhao, M. Niinomi, M. Nakai, T. Ishimoto and T. Nakano, Mater. Sci. Eng., C, 2011, 31, 1436-1444.

24 Q. Li, M. Niinomi, M. Nakai, Z. D. Cui, S. L. Zhu and X. J. Yang, Metall. Mater. Trans. A, 2011, 42, 2843-2849.

25 P. F. Xue, Y. Li, K. M. Li, D. Y. Zhang and C. E. Zhou, Mater. Sci. Eng., C, 2015, 50, 179-186.

26 M. Morinaga, N. Yukawa and T. Maya, Science and Technology, 1988, 1601-1606.

27 G. Lütjering and J. C. Williams, Titanium, Springer, 2003, p. 22.

28 S. Neelakantan, E. I. Galindo-Nava and D. S. Martin, Mater. Sci. Eng., A, 2014, 590, 140-146.

29 S. Hanada, N. Masahashi and T. K. Jung, Mater. Sci. Eng., A, 2013, 588, 403-410.

30 A. V. Dobromyslov and V. A. Elkin, Scr. Mater., 2001, 44, 905910.

31 R. Davis, H. M. Flower and D. R. F. West, J. Mater. Sci., 1979, 14, 712-722.

32 P. J. Bania, Beta-titanium alloys and their role in the titanium industry, JOM, 1994, 46, 16-19.
33 M. Chen, E. L. Zhang and L. Zhang, Mater. Sci. Eng., C, 2016, 62, 350-360.

34 L. Wang, W. J. Lu and J. Qin, J. Alloys Compd., 2009, 469, 512518.

35 Z. X. Du, S. L. Xiao, L. J. Xu, J. Tian, F. T. Kong and Y. Y. Chen, Mater. Des., 2014, 55, 183-190.

36 I. Weiss and S. L. Semiatin, Mater. Sci. Eng., A, 1998, 243, 4665.

37 J. C. Williams, B. S. Hickman and H. L. Marcus, Metall. Mater. Trans. B, 1971, 2, 1913-1919.

38 M. Pankuch, R. Bell and C. A. Melenders, Electrochim. Acta, 1993, 38, 2777-2779.

39 I. Milošev, T. Kosec and H. H. Strehblow, Electrochim. Acta, 2008, 53, 3547-3558.

40 Y. Tanaka, M. Nakai and T. Akahori, Corros. Sci., 2008, 50, 2111-2116.

41 Y. L. Zhou, M. Niinomi and T. Akahori, Mater. Sci. Eng., A, 2005, 398, 28-36.

42 D. D. Macdonald, J. Electrochem. Soc., 1992, 139, 3434-3449.

43 Y. L. Zhou and M. Niinomi, Surf. Coat. Technol., 2009, 204, 180-186.

44 D. Q. Martins, W. R. Osório, M. E. P. Souza, R. Caram and A. Garcia, Electrochim. Acta, 2008, 53, 2809-2817.

45 E. N. Codaro, R. Z. Nakazato, A. L. Horovistiz, L. M. F. Ribeiro, R. B. Ribeiro and L. R. O. Hein, Mater. Sci. Eng., A, 2003, 341, 202-210. 